\title{
DE LA NOCIÓN DE METAFÍSICA Y EL MÉTODO EN LONERGAN
}

José Manuel Orozco Garibay*

Dice Francisco Galán:

Con la distinción entre posiciones y contraposiciones que mencionamos en el capítulo anterior ya es posible introducir la definición de la metafísica. Para ello, se establece una comparación entre la noción de ser y la metafísica: "Así como la noción de ser subyace a todas las demás nociones, penetra en ellas y las trasciende, así mismo la metafísica es el sector del conocimiento humano que subyace a todos los demás sectores, penetra en ellos, los transforma y unifica". ${ }^{1}$

Según Galán, aparentemente Lonergan hace una comparación entre las dos nociones, pero en realidad no hay una correlación exacta entre ser y metafísica en tanto que nociones. De lo que se habla es de que la metafísica está por debajo o en la base de todos los departamentos del conocimiento, científico o de sentido común. Lo que llama la atención es la siguiente afirmación: "ya que los principios de la metafísica no son ni términos ni proposiciones ni conceptos o juicios, sino el puro deseo de conocer, impulso desapegado que se despliega en la conciencia empírica, intelectual y

*Departamento Académico de Estudios Generales, ITAM.

${ }^{1}$ Francisco Vicente Galán Vélez, Una metafisica para tiempos posmetafisicos. La propuesta de Bernard Lonergan de una metametodología, 2015, México, Universidad Iberoamericana, p. 179. En adelante, las citas se consignarán en el texto entre paréntesis. 
racional del sujeto autoafirmante" (p. 180). Quiere decir que la metafísica no es una ciencia constituida por términos, conceptos, proposiciones, ordenados en forma de sistema en la base de todos los sistemas. Es el deseo de conocer a partir de la experiencia, el aparato intelectual y la reflexión crítica del sujeto que se afirma a sí mismo como tal. Y es extraño decir que el deseo de conocer es la metafísica. Pero es que de ese impulso desapegado proceden todas las preguntas, intelecciones, formulaciones y reflexiones de todos los departamentos del saber. De modo que si comprendemos las condiciones de ese impulso y el método para alcanzar un saber que permita configurar la estructura cognoscitiva de la mente, entonces la estructura subyace a todos los saberes. Y eso es la metafísica. En la mente de todo sujeto hay una estructura heurística de la actividad cognoscitiva que subyace a todos los saberes científicos y ordinarios de la polimorfa conciencia humana. Y la determinación de la estructura conforme al ser proporcionado es lo que estudia la metafísica. Si todos los saberes provienen de la misma fuente, y son coherentes y compatibles, es la metafísica la que busca esa compatibilidad coherente.

Penetra todos los saberes y los transforma. Transformar es traducir los descubrimientos en conocimientos precisos y formularlos con esa precisión; sobre todo, los nuevos conocimientos. El sentido común es víctima de imprecisiones y sesgos, desatiende los consejos teoréticos. Por eso, un saber metafísico norma las bases para que se eliminen los obstáculos al conocimiento científico teorético. La metafísica tiene una función terapéutica: surge del deseo de conocer, es libre de restricciones inherentes a puntos de vista particulares, distingue posiciones de contraposiciones, busca el desarrollo de las posiciones, rompe encadenamientos que determinan saberes. La metafísica no es terapéutica en el sentido del neopositivismo que pretende eliminar expresiones metafísicas del discurso de la ciencia, sino que aclara las expresiones con la intención de eliminar las incoherencias y contraposiciones, y unificar todos los departamentos del conocimiento humano.

La metafísica en forma latente es el desenvolvimiento de la conciencia empírica, intelectual y racional impulsado por el deseo de conocer, 
y es principio operativo de todo conocimiento humano. Que haya una unidad de la conciencia empírica, intelectual y racional, permite unificar todos los saberes, de acuerdo con la operación del conocimiento humano deseado. La capacidad de hacer esa unificación, surgida de la unidad de la conciencia y su impulso por conocer, es la metafísica. Lonergan confiesa que no hay un principio definido que unifique todo, no se ha desarrollado esa técnica. Pero el impulso unificador desde la unidad de la conciencia es la metafísica latente. La metafísica es problemática porque la necesidad de contar con una sistematización de los esfuerzos de unificación es justamente algo que parece inalcanzable. Falta una normatividad del conocimiento humano. La metafísica en forma explícita distingue entre ser proporcionado y ser que trasciende los límites de la experiencia humana. Dice Galán:

Ser proporcionado es lo que es cognoscible a través de la experiencia humana, el aprendizaje inteligente y la afirmación razonable. El ser trascendente no puede ser conocido a través de la experiencia humana ordinaria, aunque sí incluye el carácter de inteligibilidad y racionalidad [...] En efecto, Lonergan señala que se pueden simplificar enormemente los problemas para el lector si por el momento nos atenemos al ser proporcionado. [p. 182]

La metafísica explícita trata del ser proporcionado al conocimiento basado en la experiencia humana, la intelección y la reflexión racionales, que permiten al sujeto autoafirmante construir un saber de ese ser (no de todo el ser). La metafísica hace afirmaciones sobre el deseo de conocer el ser proporcionado a la experiencia humana, sin entrar en la disputa sobre los límites del conocimiento humano. Galán expone la idea de la estructura heurística general en los ocho comentarios de Lonergan en torno a la metafísica. Lonergan distingue entre conceptos derivados y primitivos. Los derivados se explican apelando a los primitivos. La metafísica esclarece los conceptos primitivos a todo saber. Para eso hay que hacer preguntas previas a toda respuesta, pues preguntar es la operación cognoscitiva más importante del ser humano. 
Preguntar como acto que antecede a lo conocido, como anticipación de lo desconocido. Dice Galán:

Tenemos, entonces, algo que es aún desconocido; tal es el contenido conceptual de la respuesta, pero tenemos una anticipación de las características generales por las que tal contenido será conocido [...] Por estructura heurística se entiende una serie ordenada de nociones heurísticas. La noción de ser proporcionado es una ilustración de lo que es una estructura heurística. Cuando se nos dice que el ser proporcionado es lo que se puede conocer a través de la experiencia, la captación inteligente y la afirmación razonable, no se nos dice cuál sea el contenido así experimentado. [p. 184]

Pareciera que los conceptos ordenados del ser proporcionado, experiencia humana, captación inteligente, acto intelectivo, crítica reflexiva, afirmación racional, constituyen una estructura que nos habla del ser proporcionado sin decirnos cuál es el contenido de ese ser ni de cada concepto como tal, menos aún de la experiencia concreta. Por eso es una estructura que orienta a conocer lo desconocido del ser proporcionado. Eso es la metafísica. Indicar una serie de actos a través de los cuales uno conoce lo que es el ser proporcionado.

La metafísica es el esfuerzo por concebir tal estructura heurística integral. Busca una estrategia de implantación de la estructura. Ha de ser una metafísica progresiva en el sentido de ir descubriendo la estructura en los saberes, no es innata ni a priori, aunque la estructura sugiere que hay una serie ordenada de conceptos que permiten ir a lo desconocido y que la actividad cognoscitiva funciona de acuerdo con la estructura, que no se conoce por intuición, sino que se descubre operando en los saberes y como condición cognoscitiva de la mente humana. No es una condición trascendental del aparato, en sentido kantiano, pero es la realización de la operación cognoscitiva humana que procede de acuerdo con una estructura cuyos contenidos conceptuales se van descubriendo en las diversas operaciones que se van desarrollando. Es a priori en el sentido de que el conocer funciona de acuerdo con la estructura heurística, pero no en el sentido de un conocimiento dado de 
antemano. La metafísica distingue las partes, se refiere a los hechos por cuanto el ser proporcionado es lo que de hecho es. Depende de la ciencia y del sentido común. Trabaja con los resultados de la ciencia y del sentido común para darles coherencia, eliminar contraposiciones y descubrir la operatividad de la estructura en ellos. Además, la metafísica ha de ser estable. No está sujeta a cambios revolucionarios como las ciencias y sus períodos normales a la Kuhn. La metafísica descubre e implanta la estructura en cada estadio del saber de las ciencias, pero no hay un estadio superior a la metafísica misma. No acaece un desarrollo histórico de la metafísica, pues su contenido no es meramente conceptual, pensado o afirmado, sino heurístico. No es descriptiva, sino que explica fundamentalmente las relaciones de las cosas entre sí. Porque las ciencias comienzan describiendo y alcanzan el punto de explicación en el que las relaciones se muestran, y ahí es donde la metafísica señala que lo importante es entender las relaciones de las cosas mismas.

A partir de unos materiales provistos por la experiencia se llega a las relaciones. La idea es llegar a explicaciones cuantitativas libres de cargas afectivas, culturales, contextuales, expresadas en ecuaciones diferenciales. La metafísica explica que así se llega a conocer en la ciencia. La metafísica busca saber lo que uno conocerá cuando uno entienda —dice Francisco Galán-, y es primariamente explicativa. Pero la metafísica también incluye la concepción del ser como descrito y luego explicado. Lonergan pone las características que han de tener las relaciones descriptivas. Y la inclusión de esas relaciones descriptivas es intelectual, no experiencial. La metafísica, entonces, necesita categorías que no sean descriptivas y ya, como las aristotélicas, y tampoco le compete defender la realidad de las cualidades sensibles. Se trata de una metafísica cuyos conceptos comprendidos en la estructura heurística del ser proporcionado dan cuenta de las relaciones descriptivas y las inteligibles al modo como lo hacen las ciencias modernas. Va más allá de Aristóteles y de Tomás de Aquino. 


\section{Del método}

Dice Francisco Galán:

Un método es una serie de directivas que sirven para guiar un proceso hacia un resultado. El resultado hacia el que ahora pretende llegar es la metafísica explícita, que consistirá en: a) Una indicación simbólica del rango total de la experiencia posible, b) Una serie de actos de intelección que unifiquen tal experiencia, c) Alcanzar el virtualmente incondicionado en una afirmación razonable del panorama unificado. [p. 191]

La metafísica es de nuestra experiencia y pretende simbolizarla. La estructura heurística pretende que los actos de intelección unifiquen la experiencia como comprensible, y además hay que afirmar tanto la experiencia como lo unificado conociendo lo virtual incondicionado. La metafísica es un logro personal, está en la mente de las personas, no en un libro. Es un proceso de lo latente a lo explícito. Primero, el sujeto polimórfico está perplejo; segundo, el sujeto aprende a distinguir entre el conocimiento que comparte con los animales y el humano; tercero, recurre al deseo de conocer anterior a todo conocimiento como norma; y cuarto, es un deseo que experimenta en su ser como operante, actuante.

El paso de la metafísica latente a la explícita implica integrar los saberes para conocer el ser proporcionado. El método es un silogismo que indica condiciones para alcanzar la integración. 1) Premisa mayor. Isomorfismo entre la estructura del ejercicio del conocimiento y estructura de lo conocido. Se parte de que las relaciones entre los actos intelectivos y las relaciones entre los contenidos de los actos son isomórficas. Dice Galán: "Todo aquello que conoce y habrá de conocer tiene necesariamente una estructura similar a la de las actividades por las que conoce" (p. 195). 2) Premisa menor. El conocimiento como actividad es un conjunto - dice Galán- de operaciones relacionadas y recurrentes de un sujeto autoafirmante. Tres operaciones: experimentar, entender y juzgar. Cada posible instancia de conocimiento del ser proporcionado a nuestra estructura cognoscitiva recurre a esas tres 
operaciones. 3) Premisa menor secundaria. Los materiales de los que parte la información para que opere la actividad cognoscitiva humana provienen de la experiencia, los aportan las ciencias y el sentido común. El método contempla esos materiales para comprender el modo como son experimentados, entendidos y razonados, de suerte que el sujeto autoafirmante conozca el ser proporcionado. Además, cada ciencia sigue un método peculiar; la metafísica opera conforme a un método universal, de modo que el sujeto autoafirmante del ser proporcionado lo conozca siguiendo la idea del isomorfismo, el uso de las operaciones cognoscitivas y los materiales de experiencia. Un ser humano inteligente puede comenzar por los materiales, y desde las afirmaciones científicas llegar a descubrir las estructuras a las que esas afirmaciones de las ciencias no pueden escapar. El método permite conocer los objetivos y propósitos de la metafísica. Y la metafísica es dinámica, busca integrar el conocimiento, la ciencia y el sentido común, encontrar rigor en el examen del conocimiento adecuado al ser proporcionado: el objetivo es reorientar a la ciencia y al sentido común.

Se trata de examinar el deseo de conocer del ser proporcionado, comprender la conciencia polimorfa humana, entender la estructura heurística que subyace a las afirmaciones racionales del ser proporcionado que realiza el sujeto autoafirmante. Dar cuenta de la experiencia, el entendimiento y la razón no como trascendentales, sino como operaciones cognoscitivas de toda mente humana. La metafísica esclarece el rigor de conocer el ser descubriendo la estructura cognoscitiva de la mente humana. Y su método es único y dinámico. Parte de las ciencias y el sentido común, los integra en un todo unificado y aprehende el ser proporcionado cuya experiencia es igualmente unificada.

La metafísica latente está siempre ya operando como una anticipación de la meta del conocimiento, con independencia de todas las posturas explícitas respecto de la metafísica. En la transición que se pretende hacer de la metafísica latente a la explícita, no se parte de un ideal del conocimiento humano fijado arbitrariamente por una teoría, sino "de un ejercicio fáctico que cualquier investigador puede verificar en su propia conciencia empírica, inteligente y racional" [...] Ahora bien, para un tratamiento cabal del método de la metafísica, tampoco basta criticar otros 
métodos. Existe una dialéctica más profunda que invita al desarrollo de las posiciones así como a la reversión de las contraposiciones [...] esto necesita una objetivación de la metafísica implícita, un autoconocimiento de la propia estructura dinámica cognoscitiva, para captar sus exigencias normativas y, desde ahí, discernir de las diversas posturas sus logros y aciertos. [pp. 198-199]

Se trata de examinar en la propia conciencia la estructura cognoscitiva para encontrar el método heurístico del conocimiento del ser proporcionado. No a partir de una teoría previa y sí analizando la estructura a partir de nuestra conciencia empírica, de nuestra inteligencia y racionalidad. El análisis permite determinar el método, y luego, examinar las posiciones y contraposiciones, los aciertos y desaciertos de los diversos métodos, para fijar el método de la metafísica que, para Lonergan, es el examen del autoconocimiento. Los métodos que no son adecuados son: deductivo, deductivo concreto, deductivo trascendental, la duda universal, el empirismo y la dialéctica hegeliana.

El método deductivo encuentra en la conclusión lo que ha puesto en las premisas; el deductivo concreto pone la existencia en las premisas y arriba a la conclusión de lo existente (el monismo de Spinoza supone 166 una sustancia y sus modos y atributos, pero sus conclusiones asumen el monismo del que parten en cada argumentación de la Ética incurriendo en petición de principio — es deductivo_-; el empirismo fragmenta el conocimiento en impresiones sensoriales y hábitos de relación entre ellas; pero lo presentado por los sentidos no es lo objetivo, inteligible, universal. Escoto invita a ver lo que está ahí, pero ahí no está lo universal inteligible, luego nada dice de lo real. Todo se reduce a analizar conceptos que se abstraen de lo dado para compararlos y ver cuáles son incompatibles y cuáles no en todos los mundos posibles; pero si queremos conocer el mundo actual necesitamos una intuición de lo existente como existente y presente, una deducción concreta).

Hay una diferencia entre la extroversión y la objetividad. Ir por el lado racional o ir a lo ya-afuera-ahí-ahora-real cuyo criterio de verdad es la sensación. Lo objetivo que depende de relaciones racionales entre conceptos aplicados a la experiencia difiere de lo dado ya-afuera-ahí- 
ahora-real. Kant está partido en dos (corazón dividido) con su deducción trascendental, pues afirma que lo objetivo son las cualidades primarias y secundarias de los fenómenos en el espacio y el tiempo como formas a priori de la sensibilidad, sin que el conocimiento de las cosas en sí mismas sea posible. La necesidad de ir a lo afuera-ya-ahí-real es el fenómeno (extroversión), pero la cosa queda fuera del alcance del conocimiento, y lo inteligible es una mera idea reguladora. En la duda de todo (Descartes), hay varios problemas: si se busca lo indubitable entonces no puede haber juicios concretos de hecho porque se excluye la posibilidad de que haya más preguntas relevantes sobre el hecho, y como siempre las hay, entonces todo juicio será dubitable; las ciencias y el sentido común se basan en juicios de hecho, y si se busca lo indubitable, ciencia y sentido común serían imposibles; dado que no se aclara qué es "conocimiento", "objetividad" y "realidad", todo juicio deviene oscuro; todo lo meramente supuesto es indubitable, pero si es supuesto se comporta como una proposición analítica. El sujeto existencial es el núcleo de las operaciones experimentales, inteligentes y racionales, y si lo que se obtiene son juicios dudosos, entonces el sujeto ve con frustración el fracaso de ese núcleo; el criterio de indubitabilidad es indubitable; cada razón para dudar es dubitable; aceptar lo indubitable es casarse con el juicio sin ver las consecuencias. La mente tiene un pasado, un saber de sí misma, que no se puede poner en duda, y si los juicios de una mente no son dudosos, los de otras mentes parecerían dudables, de suerte que lo difícil es ver lo dudable de las propias creencias.

En cuanto al método del sentido común, Lonergan recuerda que es el centro original del proceso filosófico; rechaza lo teorético, el buscar síntesis elevadas y últimas. En lugar de soluciones definitivas, el sano sentido quiere que tengamos juicios prudentes, y eso no es desdeñable. El sentido común aporta las premisas menores secundarias del silogismo metódico, o sea los materiales de los que se parte para alcanzar la integración posterior. Pero se admite que el sentido común usa confusamente los términos y tiene sesgos subjetivos. Ya depurado de eso, el sentido común aporta juicios prudentes de materiales de los que se 
parte para entender y razonar. Sin embargo, dice Galán: "El eclecticismo de sentido común aniquila el objetivo de la filosofía de buscar un desarrollo del deseo puro y desapegado de conocer que sea integrador" (p. 211).

Decíamos que hay que distinguir entre extroversión y objetividad. Un punto de vista extrovertido no se separa del supuesto animal de lo afuera-ya-ahí-ahora-real dado a los sentidos; en cambio, la objetividad se vale de juicios en los que opera el entendimiento (lo inteligible) y la razón (el análisis crítico). Cuando lo extrovertido se confunde con lo objetivo, como en el sistema hegeliano, en el que todo lo real es racional, la res extensa y la res cogitans son idénticas. Entonces, lo afuera-yaahí-ahora-real se reduce a la expresión del concepto en su despliegue dialéctico hacia el autoconocimiento absoluto de un sistema cerrado. Los diferentes patrones de experiencia quedan absorbidos por el patrón intelectual del desarrollo del concepto en su objetivación. Pero el peso exagerado del concepto pierde su separación con lo real. Así refuta Lonergan a Hegel. En suma, la clave hermenéutica de Lonergan la describe Francisco Galán:

Convencido de haber encontrado una clave hermenéutica fundamental, menciona Lonergan los puntos en que su teoría supera la epistemología propia de la filosofía moderna: a) elimina la rigidez del a priori kantiano; b) descubre la captación de lo incondicionado como esencial para el juicio; c) identifica la noción del ser con el ímpetu de la pregunta inteligente y de la reflexión crítica; d) define la metafísica por la estructura heurística integral de dicho ímpetu; e) y rescata a la filosofía como el conocimiento universal sin infringir la autonomía ni de las ciencias ni del sentido común. [p. 215]

La integración la busca la filosofía y lo mismo la ciencia. Pero los científicos buscan un patrón unificador de integración de los saberes y su universalización yendo más allá del sentido común, por lo que usan un lenguaje técnico. Si en un tiempo los científicos desechaban el sentido común y trataban de integrar los saberes mediante la ciencia unificada, confundían la objetividad con la extroversión y la realidad con una 
subdivisión de lo ya-afuera-ahí-ahora-real, ya es tiempo de dejar atrás el mecanicismo y el determinismo, y, como dice Lonergan, comprender la importancia de la aparición histórica de las prácticas cognoscitivas. Hay que explicar en términos de probabilidad y leyes necesarias, poner en duda la necesidad psicogénica de hacer exégesis deterministas, rescatar la importante teoría de la relatividad en la definitiva remoción para la física de una concepción imaginativa y no inteligible del espacio y el tiempo, ver la mecánica cuántica que remueve cualquier visión de las partículas. El monismo científico cree en una visión unívoca y estrecha del conocimiento, cuando de lo que se trata es de integrar las ciencias a partir del reconocimiento de sus métodos y visiones cambiantes. La filosofía debe usar un método riguroso, pero no el de la ciencia. La filosofía debe distinguir entre filosofía y ciencia, de suerte que se comprenda el rigor que puede tener una filosofía cuyo objeto es único frente a las ciencias con objetivos diversos. La filosofía busca la visión integral; las ciencias no pueden llegar a un saber integral de todos los saberes. La filosofía llena de contenido una estructura heurística frente al método científico de las ciencias. Otro problema es el del polimorfismo de la conciencia humana que explica que el significado de términos como "conocimiento", "realidad" y "objetividad" puede dar lugar a posturas diversas. Un lenguaje técnico de la filosofía tendría que analizar toda la gama de posibles significados de esos términos, valoraciones y combinatoria de variables, valores y posturas. Aún más, contar con un lenguaje técnico de la filosofía requiere un metalenguaje que lo explique.

Otro problema es pensar que los científicos comparten creencias comunes basadas en su mentalidad conservadora. Como un científico no puede conocer todo lo que abarca su ciencia, entonces tiene que confiar en su tradición. El progreso científico parte de la creencia en la tradición. En cambio, la filosofía se hace desde la tradición. Varias tradiciones se mezclan en el ejercicio de la filosofía. Y el conocimiento filosófico es personal. El científico no logra el autoconocimiento que alcanza el filósofo.

En conclusión, el aporte de la ciencia a la filosofía no está en que la filosofía trabaje como la ciencia, sino en darle instancias de estructuras 
heurísticas únicas, las cuales deberá integrar el metafísico y no el científico. Si bien la filosofía se ha fecundado repetidamente con los logros científicos, no por ello ha de esperarse que se conforme con el método, con la técnica lingüística o con la mentalidad grupal del científico. [p. 220]

\section{Corolario sobre el lenguaje: rebasar a Wittgenstein}

\section{Dice Francisco Galán:}

La tarea central de la metafísica sigue siendo la integración, pero ahora no solo de los materiales que provienen de las ciencias, sino también de los materiales provenientes de las distintas filosofías e incluso de los diferentes puntos de vista de las diferentes culturas [...] Una característica general, y que permanentemente recurre en la vida humana es que haya una cierta conciencia sensitiva y una respuesta simbólica a lo "conocidodesconocido" [...] La metafísica está condicionada por el autoconocimiento y este, a su vez, lo está por el desarrollo humano. Una metafísica explícita y adecuada es un corolario del autoconocimiento explícito y adecuado. Ya sabemos que una metafísica explícita y adecuada se sigue de lo que llamamos nuestra "base", esto es: a) De la afirmación de uno mismo como una unidad consciente de manera empírica, inteligente y racional, b) De la definición heurística del ser, que revela que la afirmación inteligente y razonable es un conocimiento de la realidad, c) De la formulación de la objetividad como experiencial, normativa, absoluta y principal, que despoja a las contraposiciones de su aparente plausibilidad [...] Lo que le falta al autoconocimiento y a la metafísica cuando no se ha dado un desarrollo humano suficiente son: 1) elementos para la auto objetivación lingüística; 2) un ambiente cultural para el control de significados abstractos; 3) percatarse del polimorfismo y de sus posiciones y contraposiciones; y 4) conocer esta dialéctica. [pp. 331-341]

Lo primero que destacamos es que la metafísica busca integrar los saberes de las ciencias y del sentido común. Pero ¿qué significa integrar? Tener todos los saberes de las ciencias y del sentido común para alcanzar un saber que contenga todos los saberes es algo absurdo; es posible que 
"integrar" se refiera a que los materiales que surgen de las ciencias y del sentido común se contemplen como susceptibles de ser experimentados, entendidos y razonados de acuerdo con una estructura que explique que el sujeto va de lo desconocido a lo conocido gradualmente, y que adquiere afirmaciones inteligentes acordes a saberes del ser proporcionado. Que esa estructura está en nuestra mente no es una condición trascendental, sino una serie de conceptos que determinan las operaciones cognoscitivas que permiten aprehender el ser, y eso se da en todo sujeto. Asumiendo eso, el estudio de la estructura heurística que permite las operaciones cognoscitivas que aprehenden el ser proporcionado a los saberes mediante afirmaciones inteligentes, es la metafísica explícita. Pero además, no solo parte de materiales que aportan las ciencias y el sentido común, sino de las diferentes culturas. La metafísica responde a las culturas. Eso no quiere decir que haya una metafísica para cada cultura, sino que las diferentes culturas pueden ser expresadas desde la metafísica. Hay un sujeto que se observa a sí mismo, criterios de objetividad normativa, afirmaciones inteligentes del ser proporcionado y conciencia polimorfa. Aparte, los actos mentales o intelectivos tienen que expresarse en un lenguaje. Lonergan diferencia entre lenguaje ordinario y lenguaje original ordinario. O mejor, entre significaciones del lenguaje ordinario y la significación original del lenguaje ordinario, que se opone al lenguaje literario y al lenguaje técnico. Eso quiere decir que el lenguaje cambia, se desarrolla, crea nuevos significados a partir de significaciones segmentadas y viejas, e inventa nuevos vocablos a partir de los existentes. Los poetas toman palabras y les dan sentidos semánticos específicos como asociar verde con vida. Las palabras de las ciencias luego se usan en el lenguaje ordinario, y se dice "complejo de Edipo", "supernova", "peso específico", "variable", como si nada. La comunicación de términos o palabras técnicas se reduce a un grupo de especialistas; las palabras literarias se dan en la experiencia estética de la lectura. Pero en filosofía, Lonergan dice que los problemas filosóficos se expresan en actos mentales por medio de actos de lenguaje, expresiones del lenguaje. Muchos problemas del lenguaje deben analizarse para aclarar los actos mentales de que se 
trata. La postura que examina el lenguaje en su significación ordinaria habitual, apelando a la sintaxis, la gramática y la semántica, no comprende que lo ordinario no es lo original, que quiere decir que hay cambios en los significados que derivan de cambios en los actos mentales de los filósofos, cambios en sus juicios e intelecciones. Negar esos actos mentales es presuponerlos. Y es aquí donde Lonergan enfrenta al segundo Wittgenstein, que sostiene que el significado depende del juego de lenguaje, de los usos de las palabras dentro de un juego, que no hay nada común a todos los juegos, y en esos contextos los significados y los actos (preguntar, ordenar) varían sin que haya criterios de significado universal. No hay univocidad del ser. Pero Lonergan parte de que hay un ser, un deseo de conocer el ser proporcionado, experiencia sensorial, entendimiento y razón, y afirmaciones inteligentes expresadas por medio de significaciones precisas. Si Wittgenstein tuviera razón habría usos y significados variantes, pero no nuevos significados que surjan a partir de nuevos descubrimientos. Cierto, un individuo que pertenece a una cultura puede jugar en los campos que se abren dentro de esa cultura, pero puede aprender a jugar esos juegos e ir más allá, por medio del conocimiento que le permite estar en el siglo XXI y en el III a.C., y moverse de un juego a otro, descubrir nuevos significados, compararlos, siempre apegado a la verdad, la objetividad, el deseo de conocer, mediante nuevos desarrollos. Por encima de los meros juegos hay conocimiento. Y los significados que derivan del conocimiento se van transformando de acuerdo con el desarrollo de ese conocimiento. Las estructuras cognoscitivas hacen comprensible el desarrollo de los actos intelectivos y las significaciones del lenguaje original ordinario.

Tampoco son condiciones trascendentales de posibilidad de la comunidad del significado, como lo pretenden Apel y Habermas, en las que una especie de sujeto colectivo logra comunicarse a partir del seguimiento de normas trascendentales que condicionan la comunicación en la comunidad. Y el juego de las condiciones trascendentales funciona por las estructuras cognoscitivas dinámicas del sujeto. En la fase de nuevas instituciones de conocimiento se controlan los significados y se desarrollan nuevos juegos deliberadamente (sin estar inmerso dentro 
de ellos en un relativismo del significado). Se trata de relacionar las cosas entre sí y no con nosotros y nuestros contextos (posmodernos).

Un modo de poner freno a esta tendencia es a través de las formulaciones precisas de conceptos abstractos, donde los términos fijan las relaciones y las relaciones definen implícitamente los términos, es decir, recurren a las definiciones implícitas. Esforzarse en hacer esto es involucrarse en el punto de vista explicativo y es una manera efectiva de rechazar las contraposiciones [...] la necesidad de captar de modo firme el carácter heurístico y progresivo de la inteligencia humana. [p. 347]

Frente al mito y el misterio está el conocimiento. No hay dos realidades, sino una que es la del ser proporcionado al deseo de conocer por medio de una estructura heurística. Eso conduce al terreno de la filosofía y la pedagogía. Se parte de asumir que se pueden enfrentar posiciones y contraposiciones, ir más allá del relativismo, dejar atrás realismos míticos, asumir el deseo de conocer basado en la experiencia, la inteligencia y la racionalidad, la capacidad del sujeto autoafirmante de hacer justo afirmaciones inteligentes, observarse uno mismo, valerse de juegos de lenguaje constituidos en los que las significaciones se desarrollan, y dinamizar las estructuras operativas del conocimiento propias de los actos mentales. La metafísica explícita nos presenta este camino para pensar en tiempos posmetafísicos. Pero no el ser trascendental, sino el ser proporcionado a las ciencias, el sentido común y las culturas, siempre desde un punto de vista universal.

El criterio de verdad consiste en captar reflexivamente el incondicionado virtual en el acto de juzgar. El concepto en la trama de juicios es claro: ese es el incondicionado. Y el despliegue del deseo de conocer es el criterio remoto de verdad. Así, hay una definición de verdad muy aristotélica, que cita Francisco Galán: "Se sigue así la definición tradicional de verdad: 'La conformidad o correspondencia de las afirmaciones y negaciones del sujeto con lo que es y no es"” (p. 353). 
